\title{
A Heterogeneous Palladium Catalyst for C2-Selective Arylation of Indoles
}

Key words

arylation

diaryliodonium salts

indoles

palladium catalysis
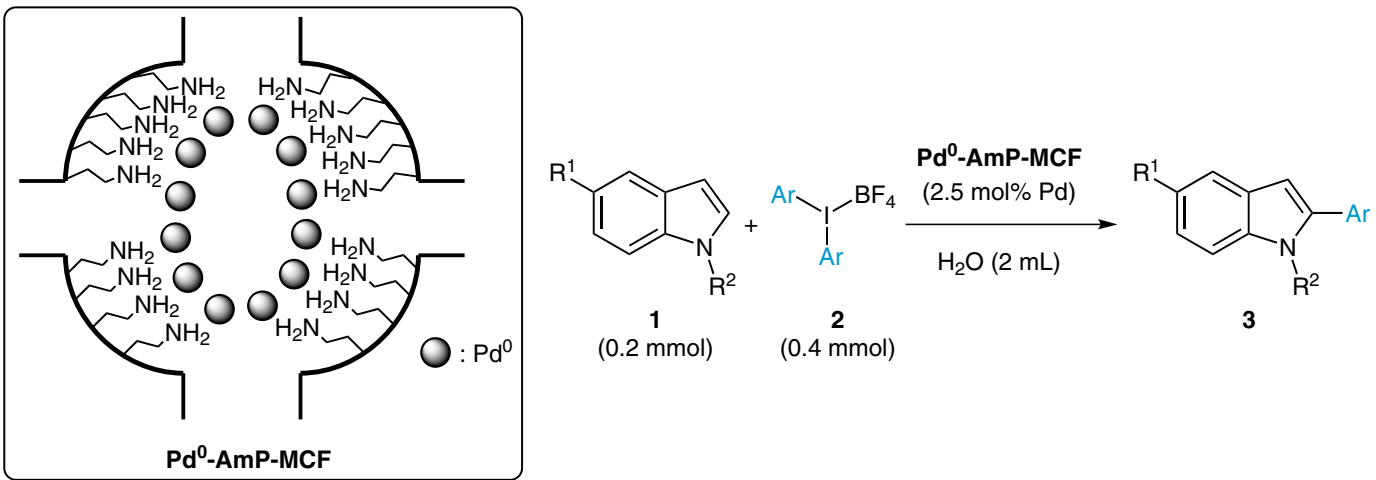

Significance: $\mathrm{Pd}^{0}-A m P-M C F$ constitutes of silica-based mesocellular foam (MCF) functionalized with aminopropylsilane (for the preparation, see: M. Shakeri et al. Chem. Eur. J. 2011, 17, 13269). $\mathrm{Pd}^{0}-$ AmP-MCF (palladium particles ø: 2-3 nm) catalyzed the $\mathrm{C} 2$-selective arylation of indoles $\mathbf{1}$ and substituted diaryliodonium tetrafluoroborates 2 to give the corresponding indole derivatives in $65-99 \%$ yield (15 examples).
Comment: The reactions of an electron-rich indole (3b), an N-methylated indole (3d), para-alkylsubstituted salts (3f,g), or an electron-deficient $\mathrm{CF}_{3}$-substituted salt (3j) afforded high yields, whereas an $\mathrm{N}$-benzylated indole (3e) or a naphthyl salt (3i) resulted in lower yield. ICP-OES analysis showed $0.6 \mathrm{ppm}$ of palladium leaching from the reaction mixture $(\mathbf{3 a})$. 